\title{
Kloake und Boudoir
}

Erhard Taverna

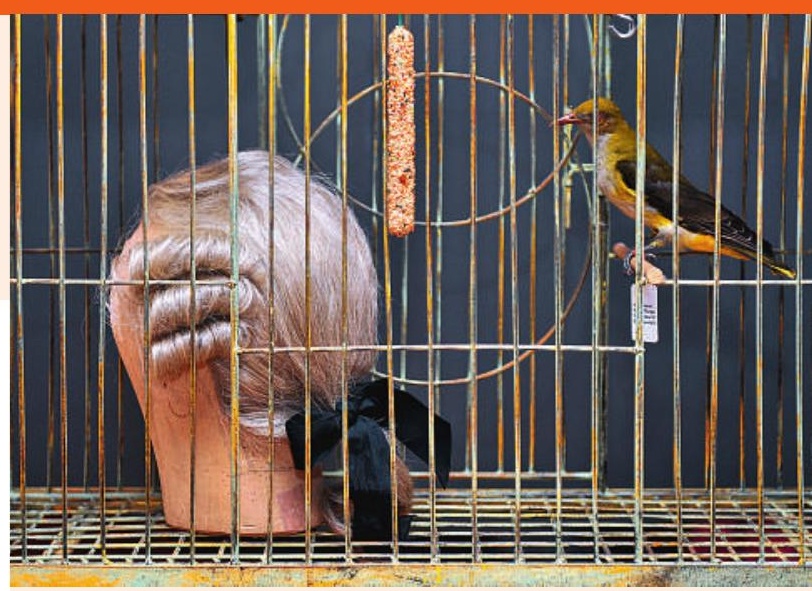

Nachts hing die falsche Haarpracht in der Voliere, damit die Vögel das Ungeziefer fressen. (๖) Kulturama, Josef Stücker

nischer. Die Stoffe waren nun so leicht, dass sich die Frauen eine Lungenentzündung holten, manche gar, wie die Kaiserin Joséphine, starben an dieser «Mousseline-Krankheit». Die neueren Funde um das Arenenberger Kaiserbad und die zugehörige Technik belegen die Fortschritte der feudalen Hygiene. Dank Napoleon III. und seiner Gemahlin Eugénie kam auch die haute couture nach Paris, und Baron Haussmann baute die ersten Abwasserkanäle der Hauptstadt. Mit der Industrialisierung und den Entdeckungen der Bakteriologen erhielten alle Metropolen effiziente Kanalisationen, die den Epidemien ein Ende setzten.

Die Ausstellung «eau \& toilette» zeigt auf engstem Raum viele Aspekte unserer Körperkultur, zu der Gestank und Wohlgeruch untrennbar dazugehören. Das Napoleonmuseum Thurgau und das Museum für Archäologie Thurgau gestalteten gemeinsam den lehrreichen Parcours durch die Kloaken und Boudoirs vergangener Zeiten. Am Ende dieser Duftspuren ist zu lesen, dass Herr und Frau Schweizer täglich 100 Liter sauberes Trinkwasser für Bad oder Dusche, Händereinigung und WC verbrauchen. Dazu geben sie jährlich 100 Franken für Parfüms aus. Eine Batterie von Kunststoffflaschen aller Grössen erinnert an die Kehrseite des Putzfimmels. Die kleine, klug konzipierte Ausstellung vermittelt eine fundierte Sicht auf die teils absurden Gewohnheiten unserer Spezies. Die zahlreichen Bezüge animieren zum Nachdenken. Es fällt uns leicht, über Versailles die Nase zu rümpfen, doch dabei übersehen wir die weit schlimmeren Folgen eigener Abfallgebräuche. Viele Stadtquartiere unserer Grossstädte stehen auf planierten Müllbergen. Millionen Menschen leben wie die Ratten vom Kehricht. Plastik und Sondermüll verpesten die Meere. Im Geschäft mit den Exkrementen einer Wegwerfgesellschaft wird nicht nur die Mafia reich. Doch das ist ein Thema für das angebotene Rahmenprogramm oder eine nächste Ausstellung.

\section{eau \& toilette - Hygiene und Schönheit} von $-\mathbf{3 9 0 0}$ bis $+\mathbf{2 0 1 2}$

Sonderausstellung bis 24. Juni $2012 \mathrm{im}$ KULTURAMA Museum des Menschen, Englischviertelstrasse 9, 8032 Zürich. Dienstag bis Sonntag 13-17 Uhr. www.kulturama.ch 